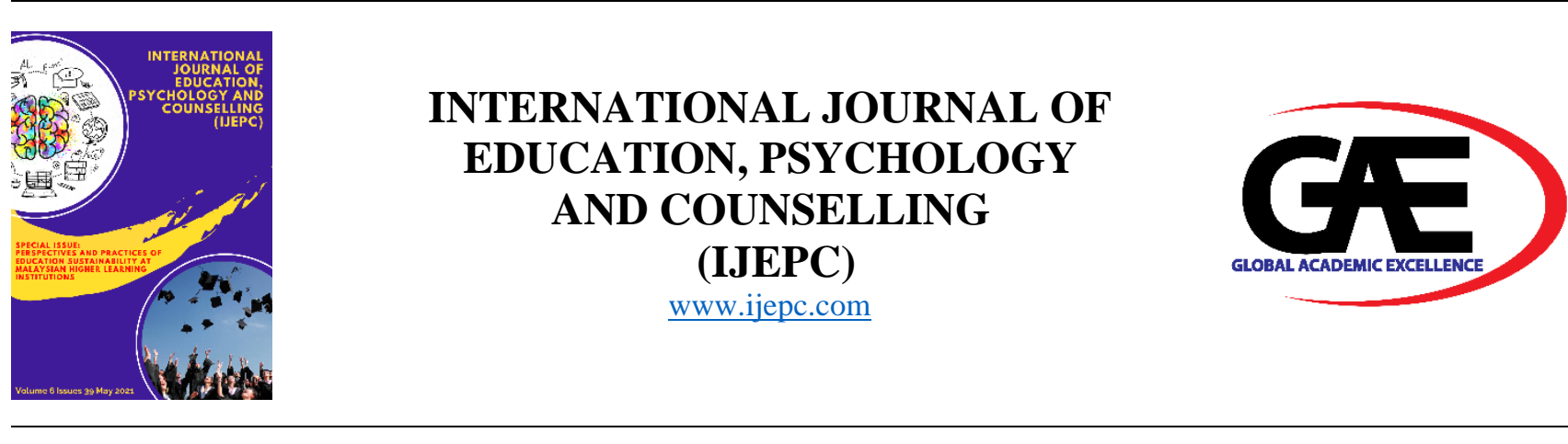

\title{
UNDERSTANDING THE CHALLENGES AND THE OPPORTUNITIES ASSOCIATED WITH LEADERSHIP DEVELOPMENT FOR STUDENTS OF HIGHER LEARNING INSTITUTION IN SABAH, MALAYSIA
}

Romzi Ationg ${ }^{1 *}$, Mohd. Sohaimi Esa ${ }^{2 *}$, Irma Wani Othman ${ }^{*}$, Mohd Kamal Mohd Shah ${ }^{4}$, Muhammad Safuan Yusoff ${ }^{5}$, Habibah @ Artini Ramlie ${ }^{6} \&$ Saifulazry Mokhtar $^{7}$

1 Centre for the Promotion of Knowledge \& Language Learning, Universiti Malaysia Sabah

Email: mrationg@ums.edu.my

2 Centre for the Promotion of Knowledge \& Language Learning, Universiti Malaysia Sabah

Email:msohaimi@ums.edu.my

3 Centre for the Promotion of Knowledge \& Language Learning, Universiti Malaysia Sabah

Email: irma@ums.edu.my

4 Faculty of Engineering, Universiti Malaysia Sabah

Email: mkamalms@ums.edu.my

5 Labuan Faculty of International Finance, Universiti Malaysia Sabah

Email: safuan_y@yahoo.com

6 Centre for the Promotion of Knowledge \& Language Learning, Universiti Malaysia Sabah, Malaysia

Email: habibah_artini@ums.edu.my

7 Centre for the Promotion of Knowledge \& Language Learning, Universiti Malaysia Sabah, Malaysia

Email: saifulazry.mokhtar@ums.edu.my

* Corresponding Author

\section{Article Info:}

Article history:

Received date: 10.03 .2021

Revised date: 15.04 .2021

Accepted date: 15.05 .2021

Published date: 31.05 .2021

To cite this document:

Ationg, R., Esa, M. S., Othman, I. W., Shah, M. K. M., Yusoff, M. S., Ramlie, H., \& Mokhtar, S. (2021).

\section{Abstract:}

The presence of effective leadership is always vital for the successful attainment of common goals. Given that the students of HLIs are the potential leaders of any organization or society in the future, leadership development programs/courses generally required in HLIs. Accordingly, in an effort to ensure the Higher Learning Institutions graduates well equipped with effective leadership knowledge and skill, the HLIs in Sabah is offering leadership development programs/courses. Despite that, however, many remain clueless of what exactly are the challenges and opportunities associated with these leadership development programs/courses. By applying a qualitative approach through the examination of information gathered from various sources such as books, journals, and media reports, the paper presents 


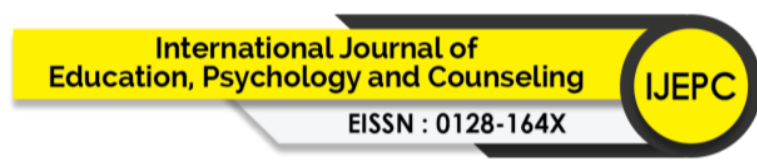

Volume 6 Issue 39 (May 2021) PP. 127-136

DOI 10.35631/IJEPC.639008

Special Issue: Perspectives and Practices of Education Sustainability at Malaysian Higher Learning Institutions

Understanding the Challenges and the

Opportunities Associated with Leadership Development for Students of Higher Learning Institution in Sabah, Malaysia. International Journal of Education, Psychology and Counseling, 6 (39), 127-136.

DOI: $10.35631 / \mathrm{IJEPC} .639008$.

This work is licensed under CC BY 4.0

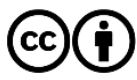

a discussion on the challenges and opportunities associated with leadership development programs/courses for students of HLIs in Sabah, Malaysia. The findings are expected to contribute to the systematic understanding of challenges and opportunities of leadership development programs/courses for students of HLIs, thus led to the enrichment of existing leadership development programs in HLIs.

Keywords:

Leadership Development; Students; Higher Learning Institution; Challenges; Opportunities

\section{Introduction}

Today, effective leadership has become so important element in any organization, including the Higher Learning Institution (HLI). In fact, scholars who focusing on leadership and education generally argued that the absence of effective leadership often made organizations resources become ineffective. This certainly suggest that, though it is not a position nor a title, but is an interactive process that needs to be effective by which a person exerts an influential dominance upon his/her followers, effective leadership is the key determining factor in the success of organization to attaining its goals. Thus, it is sensibly true that the successful organization need effective leadership. The presence of leaders who possesses effective leadership quality is crucial to communicating and implementing common goals in order to boost total organization's success (Ationg, Esa, Ibrahim \& Muis, 2020; Esa, Ationg, Hiew, Muis \& Ibrahim, 2021).

In explaining this, Di Stefano, Scrima and Parry (2019), and Distefano (2002) opined that effective leadership is invaluable quality especially in the area of strategies construction and communication to the followers as the followers really need to understand and instilled a sense of inspiration in playing their significance role to accomplish the preidentified common goals. He even stressed that the success of any organization and society is largely dependent on the leaders' ability to lead their subordinate. Larson (2012), Watson (2002), Mumford (2000), and Mumford, Zaccaro, Harding, Jacobs and Fleishman (2000) further elaborated such argument by suggesting that leadership is not necessary a super pill to the attainment of any goals, however, the leaders can make or break the society or organization. It portrays that leaders are able to create a better work atmosphere and improve followers' morale and enthusiasm to work with them for the sake of attaining the goals. The leaders' ability to coach and mentor are among the effective leaders' attributes that the followers usually seeking as they required guidelines in playing their roles. Apart from that, the leaders also set the example as an effective leader to help others see what skills they need to be a successful person. Thus, to be an effective leader, one must work with followers to not only recognize and refine their talents but also to help their followers gain more new skills as well as deepening their existing skills. In addition, the leaders also required to always ready in providing support that their followers needed to grow and develop their skills and abilities.

These are among the role the leaders must plays in the course of attaining the common goals. Some leaders might be very successful in doing their job as a leader, but some might unsuccessful. But one thing to bear in mind, effective leaders is not born, rather they are the 


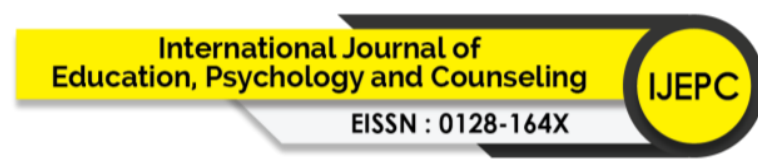

Volume 6 Issue 39 (May 2021) PP. 127-136

DOI 10.35631/IJEPC.639008

Special Issue: Perspectives and Practices of Education Sustainability at Malaysian Higher Learning Institutions product of continuous learning process. This might be the reason why scholars such as Bass (1981), Bass and Stodgill (1990) and Burns (1978) argue that the leadership development is vital as it contributed significantly in the improvement of not only the individuals but also the world. What this now hinted is that the leadership development agenda is not only provide benefit to the individuals, but is also beneficial to the world, in particular the countries and companies. Therefore, by promoting the HLIs students to leadership roles, it is expected that we already understand their capabilities, work ethic, and professional which may drive to succeed. However, if the students remain lacking the necessary skill, promoting them to leadership roles in any organizations/society will only bring risks of potentially result in the downfall of the society/organizations. They might excel in academic, but it is possible that they become unsuccessful in leadership roles.

Accordingly, leadership development programmes/courses/activities in HLIs are crucial to the long-term benefits. This is the reason why the HLIs in Sabah are offering leadership development programs/courses/activities since the beginning. Whether the programs/courses/activities actually have plays significance role to the improvement of leadership skills among the students, it certainly associated with numbers of opportunities and challenges. Thus, it is invaluable to explore the leadership development agenda in the HLIs in Sabah by focusing on opportunities and challenges associated with it. Accordingly, by applying a qualitative approach through the examination of information gathered from various sources such as books, journals and media reports, the paper presents a discussion on the challenges and opportunity associated with leadership development program/courses/activities for students in of HLIs in Sabah, Malaysia. The following section is the findings and discussion of this paper. It comprises of discussion on leadership development in the HLIs in Sabah, the concept of effective leadership, opportunities associated with leadership development in HLIs and challenges associated with leadership development in HLIs.

\section{Findings}

As explained, the finding and discussion section of this paper includes a discussion on discussion on leadership development in the HLIs in Sabah, the concept of effective leadership, opportunities associated with leadership development in HLIs and challenges associated with leadership development in HLIs.

\section{Leadership Development and the Higher Learning Institutions in Sabah}

The HLIs in Sabah are already aware of the decreasing number of graduates with effective leadership skills. This phenomenon of decreasing individual with effective leadership skills is generally contributed by the significant use of medias such as facebook and whatsapp application by the youngsters, a social media platform which prevent the graduates from engaging significantly with leadership activities. For this reason, the HLI in Sabah have decided to offer numbers of programs/courses/activities that aim at equipping the students with necessary knowledge and skills pertaining to leadership. In general, the content of the programs/courses/activities emphasising the importance of leadership skills in the attainment of any common goals. In many cases, the programs/courses/activities also required the students to understand the theoretical aspect of leadership. Some other included the practical application of the leadership knowledge via community engagement. Despite that, however, it is important to acknowledge that there still a room for improvement in the presence 


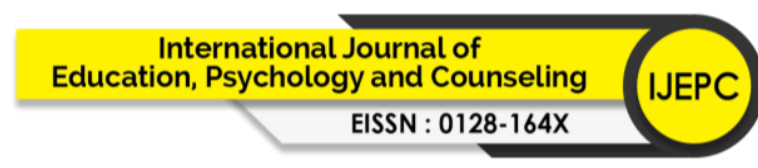

Volume 6 Issue 39 (May 2021) PP. 127-136

DOI 10.35631/IJEPC.639008

Special Issue: Perspectives and Practices of Education Sustainability at Malaysian Higher Learning Institutions leadership development programs/courses/activities in the HLIs in Sabah as the world need to have enough amount of leaders with effective leadership quality.

\section{The Concept of Effective Leadership}

The concept of effective leadership often linked with skills in which Ganta and Manukonda (2014), Grint (2007) and Ationg (2001) described as ability to be a good example or role model to their followers mainly because one with such quality usually able to effectively achieve the predetermined goals. The concept of effective leadership also linked with leader's ability to gain the trust and admiration of their followers, thus often made the followers' values, beliefs, behaviour and attitudes altered. This suggest that, leader who possess effective leadership quality is one that have the strong influence over his followers in achieving goals and objectives of the organization (Northhouse, 2009; Ationg, 2018; Ationg, Zulhaimi, Ibrahim \& Hashim, 2018).

Having said that, however, Stogdill (1974), Bass (1981), and Bass and Stogdill (1990) suggest the concept of effective leadership to be defined by many in various ways. Among the definition of effective leadership often appeared in the leadership literature is the fruitful exercise of individual influence by one that led to the accomplishment of common goals. This definition generally applies in some area such as a small-group and in a political arena Burns, 1978). Wasim and Imran (2010), however, defined effective leadership as a leader who has strong leadership character. This includes the character such as their ability to provide a clear path to their followers as well as their ability to ensure their followers to strongly pledge to their jobs in a group to accomplish common goals.

On the other hand, Jackson and Parry (2008) portrays that the concept of effective leadership refers to is a process where leaders use their knowledge and skills to not only lead but also to ensure all followers play their role according to the desired direction of the group. In addition to such explanation, Ganta and Manukonda (2014), Grint (2007) and Ationg (2001) suggest that the concept of effective leadership must be seen as the leaders who has strong leadership skills as well as be in certain position. This includes consistency, vision, trust, passion and good communication skills.

This suggest that the concept of effective leadership is also the good leaders who have the ability to drive their follower in accomplishing common goals. The reason is that the effective leaders is one that have a clear vision, characteristics and skills for the group, and therefore be able to ensure all parties within the group play their role actively in fulfilling the need of the group. What this now hinted is that effective leadership is always required for the success of any organization. Therefore, leadership development program, courses or activities in the HLIs can be described as the program, course or activity that must be improved according to the needs of the present society. This is certainly made the leadership program, course or activities in the HLIs changes according to the relevant trends, thus made it always needed due to opportunities associated with it.

\section{The Opportunities Associated with Leadership Development in HLIs}

There are numbers of opportunities associated with the leadership development in any organizations and specifically in HLIs. In explaining such argument, Lipman (2012), Mueller (2015), Tredgold (2017), and Walters and Rodriguez (2017) there are numbers of reasons 


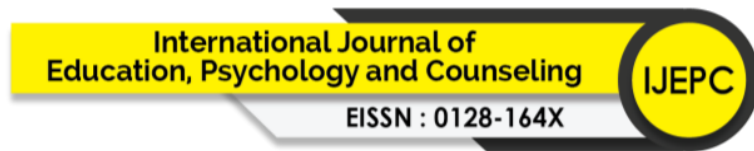

Volume 6 Issue 39 (May 2021) PP. 127-136

DOI 10.35631/IJEPC.639008

Special Issue: Perspectives and Practices of Education Sustainability at Malaysian Higher Learning Institutions why leadership development or leadership training is always needed. Here are the reasons or the opportunities associated with the leadership development/training in the organizations such as HLIs:

\section{Increase Productivity}

By attending the leadership training, it is expected that the students be able to helps other and specifically the followers increase their productivity in any specific area. Most importantly, the training also provides them knowledge of managing the society productively. The reason is that they are highly needed to provide direction to followers as well as ensure they are performing at or above expectations. Thus, by attending the training, the students will have the ability to assess hitches, manage situations, and provide sensible solutions. That is, with such ability, the leaders can increase the productivity of their followers

\section{Increase Student's Engagement}

When the HLI provide students an opportunity to experience being given a role as a leader of organizations/society's future during the class, it is expected that they will respond with loyalty. Following the completion of the training the students become more interested in engaging with the leadership role and it made them actively participating in any academic activities within the HLI.

\section{Nurture Future Leaders}

It is important to note that the HLIs is expected to be strategic about developing and nurturing future leaders of the country. Therefore, the absence of a strategy, leadership roles are often assigned to the most forward personals with dominant personalities. This made it uneasy when comes to identifying the successor of the organization leadership due to lacking in terms of quality leadership, a concept generally refers to a combination of the right qualities and the right training. But the presence of leadership training could ease such difficulty. This suggest that leadership training in HLIs helps nurturing future leaders supports succession planning and offers career pathways to students.

\section{Teach the Students Valuable Skills}

Leadership training also teaches students the skills they really need to lead effectively, including the often-tricky skills required to persuade and influence people. Most importantly, the training also widens thinking abilities to help them think in innovative and creative ways. This certainly suggest that the leadership training in the HLIs provides opportunity to gain valuable skills among the students.

\section{Helps the Students Communicate Better}

The leadership training also teaches the students how to communicate better with their peers as well as the other social groups. This helps the students realise that different people hear, respond, accept and act very differently. Accordingly, the students become more skilled in the manner in which they communicate. What this now tells us is that the leadership training aids the students to communicate well regardless of any factors so as to raise shared goals and motivate their followers to work together in attaining such goals effectively. 


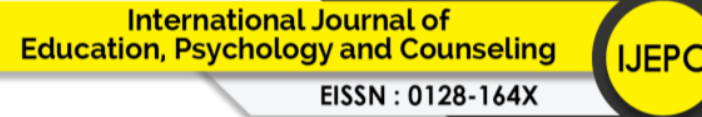

Volume 6 Issue 39 (May 2021) PP. 127-136

DOI 10.35631/IJEPC.639008

Special Issue: Perspectives and Practices of Education Sustainability at Malaysian Higher Learning Institutions Helps Develops Better Emotional Intelligence

Leadership training also helps students to develops their emotional intelligence. It is an intelligence which often describes by many as the main personality traits that makes one a great leader. Therefore, understanding how emotions affect others via leadership training ensures the students be able to lead efficiently and considerately.

\section{Provide Knowledge on How To Avoid Mistakes}

The leadership training in the HLIs also expected to give us a glimpse of the worst mistakes one can make as a leader. The training also teaches the students how to help map out a plan for evading the traps and drawbacks that can end their leadership profession.

\section{Enable Better Decision-Making}

The leadership development courses in HLIs also is expected to result in the improvement of decision-making skills among the students. The emotional intelligence improvement in which the students generally gained during the training will make them well-informed on how to deal efficiently with decision-making process. For that reason alone, the leadership training can be considered as a training that helps improve the future leader's decision-making skills.

Based on the list, it is now clear that investing in the leadership training will return a very impressive. Though, the leadership development is a process that never ends, the availability of leadership training in HLIs is significance as it associates with many opportunities.

\section{The Challenges Associated with Leadership Development in HLIs}

While there are numbers of opportunities associated with the leadership development in HLIs, it is also important to acknowledge the challenges usually associated to it. The scholars and researchers such as Sivenko (2008), Gleeson (2016), Oesch (2018) and Megheirkouni and Mejheirkouni (2020), numbers of challenges often associated with leadership training for students at HLIs. The challenges that normally hit the HLIs when implementing leadership training for students are as follows:

\section{Generic Program Content}

Many universities across the globe often offering a generic leadership development program content. They seem so excited to develop program that be able to ensure the students will be the leaders in the future. However, the transformation of human lives into a new norm no longer relevance to such program. Instead, the new world become more interested in the reallife impacts of such program. It is true that the students gain knowledge from the program and obtained certificates. This made the qualification looks wonderful, but the outdated content of the program will fail to deliver the innovative spirit the world is actually needed.

In dealing with this issue, the HLIs seems required to build its up-to-date leadership development program/courses. The HLIs should work with the business community to build a custom program. While it is required to do so, the existing program/courses might actually have an excellent framework that the new world are happy with. They might be integrated into the new learning framework which is great as it's an industry-recognized qualification once completed. The advantage of doing it this way is that leadership development program/courses in the HLIs will be very well connected with wide range of expertise and organizations. 


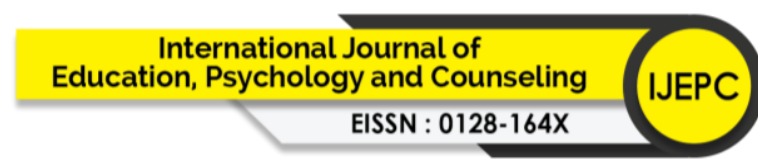

Volume 6 Issue 39 (May 2021) PP. 127-136

DOI 10.35631/IJEPC.639008

Special Issue: Perspectives and Practices of Education Sustainability at Malaysian Higher Learning Institutions

\section{Programs That Are Not Scalable}

Among the issue with the leadership development agenda in HLIs is its quality. It is clear that the new world sees such problem as more acutely due to geographical barriers presented by doing business across borders. This suggest that the HLIs are required to have brilliant leadership development program/courses, but the difficulty in accessing such training, especially when it involves practical activities but the training being conducted online, will prevent some students to gaining benefits from it. This suggest that the overall development program in HLIs will become lopsided. In many cases, it is clear that some will have the tools and others are not due to many factors. Traditional classroom-based learning is likely led to a disaster if the programs are not scalable, but if the HLIs be able to utilize the virtual learning efficiently, then the training is likely to be a bit a successful. Therefore, combining traditional and virtual learning should make the development goals of leadership development program/courses in HLIs scalable. While making it compulsory for traditional based learning activities, the teaching and learning activities can use training videos, online exercises, interactive virtual classrooms and video calls which will deliver that immersive exercise experience without physical attendance all the time.

\section{Too Much Reflection but Less Application/Practical}

The lure of leadership development programs/courses currently is to reflect profoundly on 'leadership laws' and the achievements of successful leaders without reassuring the realworld application of that knowledge. This made the leadership development programs/courses become ineffective in producing human resources actually needed by many organizations. Thus, what now the HLIs need to do is to ensure that the program/courses content are able to equip students the knowledge and skills relevance to the environments they find themselves in in the future.

\section{Discounting HLIs' Culture}

One of the problems generally affected the leadership development program/courses in HLIs is the discounting of its own culture, that is to produce highly needed individual for the betterment of the country. Most of the programs/courses seems disconnects from the local or the HLI culture. This made the training become ineffective. Therefore, there is the need that the HLIs to have a clear understanding of its culture so it can seamlessly integrate innovative approaches without estranging and disheartening their teams. To do so, the HLI might considering of having the so-called transformational leadership modules. The modules are expected to help not only the lectures but also the students understand the dynamics that affect whether the changes they want to implement will be successful or not. An excellent transformational leadership module will ensure the students to always keep one eye on what is taking place in the present-day within their teams and another eye on the kind of innovations that alter the game completely.

\section{Ignoring the Real-Life Results}

It is also important to note that the real challenge associated with leadership training in HLIs is the return of the investment. Despite the fact that the training generally expensive, the training must be seen as vital for changes. The training actually not only be able to improve the performance of any organizations but also made the participants well equipped with skills and knowledge needed for such aspiration. Accordingly, the HLI must focuses not only on 


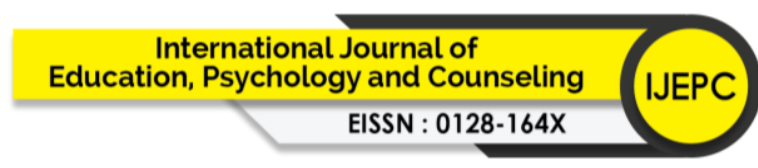

Volume 6 Issue 39 (May 2021) PP. 127-136

DOI 10.35631/IJEPC.639008

Special Issue: Perspectives and Practices of Education Sustainability at Malaysian Higher Learning Institutions soft skills such as leadership techniques and theories, but also the real-life results of the training. The training must be one that can be measured such as be able to helps the future leaders or the students improve their skills and knowledge on how to increase organization revenue, general followers/staff satisfaction and team cohesion within the organization. Thus, it is the role of the HLIs to ensure that all leadership training program being offered as a means of improving students leadership ability be clear about what are the real-life results of the leadership development program should have.

The real-life result can be vary depending on the priorities of the organization in which the country focuses on. Therefore, the HLIs must work with the organizations around the globe and specifically across the country to ensure that the content of the training will deliver the knowledge and skills actually needed.

\section{Conclusion}

This paper shows that leadership development programs/courses in HLIs in Sabah generally aim at ensuring the HLI graduates well equipped with effective leadership knowledge and skill. Therefore, it is argued that such program/courses are always vital in the HLIs in Sabah, thus made the continuous offering of the programs/courses. Accordingly, the challenges and opportunities associated with these leadership development program/courses has been the focus of discussion of this paper. It is hoped that such move helps policy makers to identify the best approach in making the programs/courses be able to add huge amounts of value to many, in particular the HLIs.

\section{Acknowledgement}

I/We acknowledge that the study in which this paper is based was funded by Global Academic Excellence (GAE) (Project Code: TLS2103; TLS2105) and Erudites Group (Project Code: TLS2011).

\section{References}

Ationg, R., Esa, M., Ibrahim, M. \& Muis, A.M.R.A (2020). Menyingkap Polemik Peralihan Kuasa Secara Luar Biasa Mengikut Perspektif Demokrasi Berparlimen. Malaysian Journal of Social Sciences and Humanities (MJSSH), 5(11), 43 - 53.

Ationg, R. (2001). Keberkesanan Kepimpinan Tempatan dalam Aktviti Pembangunan Desa di Daerah Kudat. Unpublished Master Thesis, Universiti Putra Malaysia, Malaysia.

Ationg, R. (2018). Federal Political Elites and the Expansion of Ethnic Politics to the Periphery State of Sabah in Malaysia. The Australian National University, Canberra, Australia.

Ationg, R., Zulhaimi, N.A., Ibrahim, M.A. \& Hashim, J. (2018). Leaders' Animosity and Leaders' Enviousness: An Analysis on Factor Associated with the Growing Tense Ethnic Relations in Sabah, Malaysia. Journal of Advanced Research in Social and Behavioral Sciences, 11(1), 75-81.

Bass, B.M. (1981). Stogdill's handbook of leadership. New York: Macmillan.

Bass, B.M. \& Stogdill, R.M. (1990). Bass \& Stogdill's handbook of leadership : theory, research, and managerial applications. New York : Free Press.

Burns, J.M. (1978). Leadership. New York: Harper Row.

Distefano, C. (2002). The impact of categorization with confirmatory factor analysis, structural equation modeling. A Multidisciplinary Journal, 9(3), 327-346. 


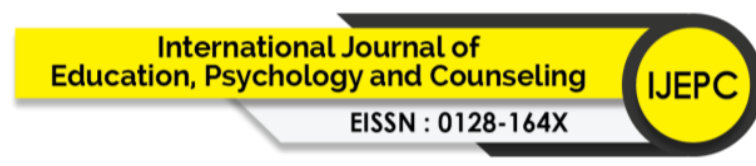

Volume 6 Issue 39 (May 2021) PP. 127-136 DOI 10.35631/IJEPC.639008

Special Issue: Perspectives and Practices of Education Sustainability at Malaysian Higher Learning Institutions Di Stefano, G., Scrima, F. \& Parry, E. (2019). The effect of organizational culture on deviant behaviors in the workplace. The International Journal of Human Resource Management, 30(17), 2482-2503

Esa, M.S., Ationg, R., Hiew, W., Muis, A.M.R.A. \& Ibrahim, M.A. (2021). Narrating the Story of Singapore in Malaysia History. Linguistica Antverpiensia, (1), 456-473.

Ganta V.C. \& Manukonda, J.K (2014). Leadership during change and uncertainity in organisations. International Journal of Organisational Behaviour and Management Perspectives, 3(3), 1183.

Gleeson, B. (2016). 3 Challenges Organizations Face in Leadership Development Today's business environment is more complex and volatile and requires a different approach to leadership development. INC. Available Online: https://www.inc.com/brentgleeson/3-reasons-why-existing-leadership-development-programs-dont-work.html

Grint. K. (2007). What is leadership? From Hydra to Hybrid. Working paper, Said Business School and Templeton College, Oxford University.

Jackson, B. \& Parry, K. (2008). A very short, interesting and reasonably cheap book about studying leadership. London: SAGE Publication, 208(2), 25.

Larson, K. (2012). Al Mohler on Conviction and Leadership. Juicy and Ecumenism. Available Online: https://juicyecumenism.com/2012/11/08/al-mohler-on-convictionand-leadership/

Lipman, V. (2012). 10 Reasons Why Companies Should Invest More in Management Training. FORBES. Available Online: https://www.forbes.com/sites/victorlipman/2012/09/10/10-reasons-why-companiesshould-invest-more-in-management-training/?sh=7584a0192471

Megheirkouni, M. \& Mejheirkouni, A. (2020). Leadership development trends and challenges in the twenty-first century: rethinking the priorities. Journal of Management Development, 39(1), 97-124.

Mueller, M. (2015). Top 10 Reasons Leadership Training is Needed. Expert Insight. Available Online: https://olivergroup.com/top-10-reasons-leadership-training-isneeded/

Mumford, M.D. (2000). Development of leadership skills: Experience and timing. Psychology Faculty Publications, 11(1), 87-114.

Mumford, M.D., Zaccaro, S.J., Harding, F.D., Jacobs, T.O., \& Fleishman, E.A. (2000). Leadership skills for a changing world: Solving complex social problems. The Leadership Quarterly, 11(1), 11-35

Northhouse, P.G. (2004) Leadership: Theory and practice (3rd. ed). London: Sage Publications Ltd.

Oesch, T. (2018). 7 Common Leadership Training Challenges and Their Solutions. Training Industry. Available Online: https://trainingindustry.com/articles/leadership/7common-leadership-training-challenges-and-their-solutions/

Sivenko, A. (2008). Contemporary leadership challenges: Talented organisation for talented People. Unpublished Master Thesis. The University of Kalmar.

Stogdill, R.M. (1974). Handbook of leadership: A survey of theory and research. New York: Free Press.

Tredgold, G. (2017). 13 Reasons Why You Need to Develop Everyone's Leadership Skills Leadership is often the difference between success and failure. INC. Available Online: https://www.inc.com/gordon-tredgold/13-benefits-of-implementing-a-leadershipprogram.html 
Volume 6 Issue 39 (May 2021) PP. 127-136 DOI 10.35631/IJEPC.639008

Special Issue: Perspectives and Practices of Education Sustainability at Malaysian Higher Learning Institutions Walters, K. \& Rodriguez, J. (2017). The Importance of Training and Development in Employee Performance and Evaluation. World Wide Journal of Multidisciplinary Research and Development, 3(20), 206-212.

Wasim, A. \& Imran, A. (2010). The role of leadership in organizational change. Relating the Successful Organizational Change to Visionary and Innovative Leadership, 3(2), 9.

Watson, D.L. (2002). Forming Christian Disciples: The Role of Covenant Discipleship and Class Leaders in the Congregation. Eugene, Oregon, United States: Wipf and Stock Publishers. 